\title{
Examination of a Failed Professional Learning Community
}

\author{
Rachel L. Sims, G. Richard Penny ${ }^{1}$ \\ ${ }^{1}$ Vice Chancellor for Advancement and External Relations, University of Washington, Bothell, WA 98011-8246
}

Received: October 14, 2014 Accepted: October 30, 2014 Online Published: December 8, 2014

doi:10.11114/jets.v3i1.558

URL: http://dx.doi.org/10.11114/jets.v3i1.558

\begin{abstract}
Schools are using various forms of professional learning communities (PLCs) in order to increase student achievement and improve educational practices through enhanced communication and collaboration among teachers. This study examined a PLC that had too narrow a focus and failed therefore to affect student achievement. A critical shortcoming of the PLC groups examined in the current study had to do with their narrow mission and definition as "Data Teams" and consequentially a constricted focus on narrow metrics. A qualitative case study design was used to gather data through 6 interviews with PLC members and 3 observations of the PLC meetings. Interview data were coded and thematically analyzed based on the research questions posed in the study. The observational data were analyzed using pre-determined categories. The results indicated that the participants perceived the PLC, in its current state, as too focused on a single set of metrics and lacking the time, collaboration, and support needed to be effective.
\end{abstract}

\section{Introduction}

Since their advent in the early to mid-1990s, professional learning communities (PLCs) have become almost ubiquitous in the world of primary and secondary education (Dufour, Dufour, \& Eaker, 2008; DuFour, DuFour, \& Eaker, 2008). With two decades of experience as a result, there is now strong evidence that the implementation of PLCs, data-driven PLCs in particular, have had positive effects on student learning outcomes (e.g. Berry, Johnson \& Montgomery, 2005; Marsh, 2010; Mokhtari \& Edwards, 2009; Vescio, Ross \& Adams, 2008). For example, Mokhtari and Edwards (2009) measured reading competency after the implementation of a PLC in an elementary school. Analysis of the student achievement data two years following the implementation of the PLC showed significant improvements. In another case, Berry et al. (2005) examined the effects of implementing a PLC at a rural elementary school over the course of four years. The authors found that students' performance improved, moving from 50\% scoring at or above grade level at the initiation of the study to $80 \%$ of students meeting grade level standards at the conclusion.

However, despite this evidence of efficacy, it is not the case that every PLC must necessarily yield benefits to students and faculty. A PLC might be unsuccessful for a variety of reasons both internal to the collaboration or externally involving environment and circumstances. Viewed through another lens, problems may lie with definition; not every gathering of teachers, even when called a PLC and held for the purpose of collaboration leading to improved student achievement, meets the criteria necessary to be an effective PLC. Dufour regretted such loose treatment of the definition as early as 2004, writing, "the term has been used so ubiquitously that it is in danger of losing all meaning" (P. 6).

With these problems in mind, there are good reasons to examine teaching collaborations that do not achieve their desired outcomes, whether these gatherings meet the definition of a PLC or not. Analysis of such failures has the potential to be instructive in the same way that analysis of airplane crashes by the Federal Aviation Administration offers potential contributions to the future safety and reliability of aviation.

In 2008, a district in Texas implemented a form of PLC known as the Data Teams Program (FBISD, 2012). The stated purpose of the Data Teams was to increase student achievement on a high-stakes test. However the process failed to increase students' test scores significantly, particularly in the case of economically disadvantaged students (FBISD, 2011). We chose to examine the teachers' experiences and perceptions with regard to the implementation of this program at one high school within the district.

\section{Methods}

A qualitative case study method was used to investigate the perceptions of teachers participating in a PLC known as the Data Team. The case study examined teachers' perceptions of the program and its effect on lesson planning, teaching, and time management. The case was confined to a single high school located in a suburb outside of a major Texas city. 
The research process collected data through multiple sources and perspectives to document experiences in a particular setting, following the recommendations of Lodicio, Spaulding, and Voegtle (2010). Data collection was accomplished through means of structured interviews and observations.

The following research questions guided the study:

1. What were the teachers' perspectives on the Data Teams program, and what effect did the program have on their experiences as teachers, particularly in the realms of teaching, lesson planning, and time utilization?

2. What steps did teachers take to complete the Data Team process?

3. Did the Data Team process change teachers' use of time both in and out of the classroom?

4. Did the Data Teams process meet the definition of a PLC, and if not, what were the shortcomings?

The targeted population consisted of ninth-, tenth-, and eleventh-grade teachers at the study school who were participating in the PLC. The PLC was implemented in the core areas of English, mathematics, and science. A total of six participants were included in the interviews and 12 in the observations. Participation in the study was voluntary, and we provided participants with an informed consent process.

We conducted six structured interviews with teachers. Four of the teachers interviewed taught English, and two taught mathematics. The interviews were 30 to 45 minutes in length and were held in the teachers' classrooms. All interviews were audiotaped and then transcribed.

We also conducted a total of three observations of the workings of PLC meetings, one within a meeting of a mathematics team and two within meetings of two different English teams. The observations examined the process of Data Teams and considered the teams' effectiveness in the arenas of shared vision, collaboration, and dialogue. The observations were conducted in each team's designated meeting area, usually a teacher's classroom, while the team conducted its Data Team meetings. The meetings were one hour in length. The observational data were collected through field notes.

Analysis of the data occurred simultaneously with the collection of the data, following the recommendations of Merriam (2009). Throughout this study, we collected small pieces of data through interviews and observations and then analyzed the material simultaneously as we collected further data. Then we combined the pieces to form a general description. Once codes were developed, we analyzed the data and codes deductively, looking for other pieces to fit within the codes. Finally we engaged in an inductive process of thematic analysis.

We assessed the credibility of the findings by the process of triangulation, using multiple sources of data collection, both interviews and observations. We also assessed credibility by doing member checks, taking our analysis back to the participants to check that the interpretations held true (Merriam, 2009). No discrepancies between the researchers' interpretations and participants emerged. A significant limitation for this study was created by the use of a single high school as the setting and the use of a small sample size. These limitations affect the generalizability of the study.

\section{Results}

\subsection{Research Question 1: Teachers' Perspectives}

The perception of the PLC varied from teacher to teacher but the overall consensus among participants was that the teams had a very narrow focus. It was the teachers' view that team meetings were concerned only with data and did not allow time for the teachers to collaborate. The following quote from Teacher 11 illustrated that point:

I think five years ago, it was much better my first year. It was more student-driven. In fact we wanted to teach students. We didn't want to necessarily get test scores, and now especially with the new STAAR test, it is mainly based on how can we make a test, or how can we make our kids pass a test that is frankly not a good representation of what they know. And so because of that, we get to teach a lot less useful material and it is more just teaching information. And I don't think that I am as effective a teacher as I was.

\subsubsection{Teaching}

Most participants said that the PLC had no effect or a negative effect on their teaching. Teacher 3 responded with, "In the nine years that I taught, I felt like I was a teacher before I became a member of this data team. And I feel I don't have a choice to be creative or do things out of structure or out of line with any other member. If it is not identical, say what this person says, do this lesson on this day in this way, and give these assignments then it's not part of the structure, and so I would I feel like it totally takes away from the motivation to even want to try something different." Another stated that she remembered to cover certain topics but that reminder was the extent of the PLC's influence on her practice. Teacher 7 said that "Would I really say it (the Data Team) has affected my teaching or the way I address my subject, no." 


\subsubsection{Lesson Planning}

All six interview participants pointed out the PLC did influence their lesson planning. Teacher 7 said, "Yes, if we find students are weak in an area then I try to address that need specifically during instruction. So I know if they don't understand a specific element, I will try to find a place that it either talks about it in our textbook so they can see it, or it's a specific assignment to try to adjust that need." Most other participants had similar responses, with one saying she differentiated more for students as a result of the PLC, and another said it helped to see the topics or concepts the students were struggling with and to address those gaps in the lesson plans.

\subsubsection{Time}

Time was seen as a negative aspect of being a part of the PLC. The lack of a common conference period was a negative for most. Teacher 11 pointed out:

Again when we had the free period, I thought it was great. I think it was great in collaboration. There's nothing bad that comes from collaboration. I think being able to bounce ideas off of one another and being able to talk with other people about what you are going to do or what your kids are struggling with [sic]. It not only creates a sense of community, it also creates a sense of wanting to strive to make sure the students are getting the best possible education from four or five different teachers. The way we have it now, we look at our students as numbers and that's it, and I think that's negative.

\subsubsection{Student Achievement}

Only one participant indicated that she thought the PLC had any effect on student achievement. Two participants responded with "no" as a response to the question. One stated that, "I don't think we create an environment where they want to achieve. I think we let them; we let them rise to the lowest common denominator" (Teacher 11).Teacher 3 said, "I don't think that it's really done anything positive for it [student achievement]; if anything, it's negative."

\subsection{Research Question 2: Completion of the Data Teams Process}

The participants reported that PLC meetings took two different forms, one where common formative assessments and data were discussed and another where the gatherings functioned as more general team meetings. Both the mathematics participants and English participants described similar processes and experiences associated with the meeting. Participants pointed out that the meetings at the beginning of the program were used to plan and discuss what worked with students. One participant noted:

If we are actually going to have a positive influence on these kids, I think we all need to get together and say: this is how I did it and it worked, this didn't work, don't do it. I mean, that was the best thing, I thought, when we worked together. I know some teams didn't but I made them come in my room every day, and we sat down, and we discussed everything that we are teaching. Did this work? Did this not work? I thought it was really good. (Teacher 4)

Without a common planning period or common conference period, the participants described the meetings as being all about data and not as effective. Teacher 11 put it this way:

At this point, it's really about looking at data and entering data. I actually think it is much less effective at this point because there is maybe a 30-minute window where we say 'Okay this [is] why I think it didn't work,' Here we just have another test. It's less about what we think will work best for the kids and how we can improve the scores, so we don't have to deal with it anymore.

One participant described the process the Data Team used when collecting data with a common formative assessment (CFA). The process of the Data Teams PLC started with creating a CFA, then giving the CFA to students. The next step was meeting with the team to discuss the results of the CFA, concentrating on students' prior knowledge and what they do not know. Lessons were then planned based on these results. At the end of the unit or topic, the same CFA was given to students. This CFA was to check for misunderstanding or missed concepts. The Data Team participants met again to discuss the post-assessment CFA results and plan to re-teach misunderstandings or missed concepts.

It was observed in the Data Team meetings that the focus of the meetings varied from student learning to failure rates to student achievement on a CFA. While all the meetings varied in their specific purpose, all had a common process and goal, to increase student achievement and plan collaboratively. The first meeting observed involved a team leader and members of the PLC for English. The team looked at standards such as Texas Essential Knowledge and Skills (TEKS) and the high-stakes test to design lesson plans for the next unit. Team members shared problems and ideas on how to address those problems. They also worked on ways to enhance curricula to meet the needs of the students. Lesson plans were developed with the help from data on the district assessment results and the requirements for the upcoming high-stakes test.

The second meeting observed ran similarly to the first, with a team leader and members but this one also involved the head of the department for English. The department chair took charge of the meeting. The purpose of this meeting was to 
discuss failure rates; again the focus was on student achievement overall. The plan for the meeting was to come up with a plan to decrease failure rates. The department head began the meeting by saying, "Failure rates are too high; we need to get them down." The participants discussed student interventions that they had taken, such as response to intervention (RTI). They also talked about specific students and brainstormed what to do with them to reduce their failures. The agreed plan for decreasing failure rates was to have a "transition stage" for incoming freshman and to implement a webpage using a program known as EDMODO for freshman parents to access.

The last observation conducted was on a second English PLC. The meeting was led by the team leader. The members were discussing a pre-assessment CFA. The participants were looking at student data, filling in a form to evaluate the CFA and student progress. Prior to the meeting, members placed students into categories of "above-proficient", "proficient", and "below-proficient." They looked at the below-proficient students first, those who made a 40, 20, or 0 on the CFA. They discussed the possible reasons why the students were struggling with the concepts they missed. The problem seemed to be that while 420 students took the assessment, not all may have missed the same concept or while one teacher's students may have missed one question, another teacher's students may have missed a completely different one. Teacher 12 said, "Look at data and maybe one misses one [of the questions], and then another, no one missed." Teacher 11 said, "Hard when results are so skewed."

\subsection{Research Question 3: Use of Time}

All the participants spoke negatively of the Data Teams in terms of time. All of the six participants spoke of the lack of a class period to complete all the work associated with the Data Team. When the program began, teachers were given a class period to work together as a PLC. After two years, that class period was taken away. The administration then gave teachers a common planning period with their team. Depending on the team, having a common planning period lasted a year to two years. As of 2013, teachers did not have a class period or a common conference period to work on the PLC.

One participant stated, "But then this year we have nothing in common. So this year is taking away every spare moment that we have because we aren't having as much time to meet to collaborate" (Teacher 3).

The process of the Data Team was to collect achievement data on its students. There are many ways the participants gathered data on their students such as CFAs, tests and quizzes, standardized tests such as high stakes tests and district assessments, as well as informal assessments. When asked how much time they spent in the classroom collecting the data members used to assess their students for the Data Team PLC, the responses ranged from 20 minutes to a full class period depending on the type of assessment and the subject.

Participants from the English PLCs stated that due to the nature of their CFA, with the students reading a passage then answering questions, it could take a whole class period for completion. Taking an entire class period to complete the CFA caused an issue for the participants due to some students completing the CFA quickly but some using the entire class period. The participants stated that they were constantly trying to figure out ways to keep the students that finished quickly engaged doing another activity, but allowing the other students to take as much time as they needed to complete the CFA.

Unlike the English PLC participants, participants from the mathematics PLCs stated that their time collecting data for a CFA was usually only five to ten minutes. Other types of assessments such as quizzes and tests could take half a class period to a full class period. One of the mathematics participants stated, regarding time needed to collect the data, "Not much, maybe five, 10 minutes on the pre-assessment and then the assessment, another 10 or 15" (Teacher 4).

Observations of the Data Team meetings showed they were efficient, being only 30 minutes to 1 hour to accomplish all the participants' goals. In the first meeting observed, the group was very open to different points of view, allowing all to give reasons of why students were failing. Responsibilities for the meetings were shared by all. For example, in the first observation, Teacher 5, department head, led the meeting. Teacher 7 seemed to contribute the most. The rest of the members of the team contributed and showed respect and collaboration on planning next paper (assignment). When planning for the alternative assignment for students who were failing, Teacher 9 said "How about we take turns giving the alternative assignment and rotate (tutorial times)..."

\subsection{Research Question 4: Meeting the Definition of a PLC}

Current research has shown the key components to maintaining and using a successful PLC are trust, support, collaboration, having a shared vision, and being practical and applicable (Cranston, 2009; Fullan, 2007; Hawley \& Rollie, 2007; Richmond \& Monokore, 2011). Communication is therefore an important factor in a PLC. The atmosphere and stability of a PLC is based on the relationships and emotions of the teachers (Webb et al., 2009). During the observations of the Data. Team meetings, communication among all team members was professional. The setting for all the meetings was conducive to a meeting with the desks arranged in a circle. One team member did not control the meeting; all contributed and discussed before coming to agreement on topics such as a practice test for the upcoming 
high-stakes test, lesson plans for the next unit, or reasons for achievement or lack of achievement on the CFA.

While the team leader or department head lead the PLC meetings and kept everyone focused and on task, all contributed to the discussion. All participants gave ideas of why students were failing in the observation. They also gave ideas of how to prevent failures and how and why the students were failing. Comments such as "\#2 we missed across the board"; "People didn't miss 3 and 1", and "That is what they usually miss, so that's good" were used throughout the meetings. The members were focused and contributing to the meeting's agenda.

Collaboration was evident throughout the third meeting we observed. All contributed ideas to why students were struggling or why students missed questions as well as why students got some questions correct. Throughout the meeting comments such as " (The students) got stuck on vocabulary"; "We need to work on layering", and "Talk more in class, more verbal" showed the collaboration. The participants collaborated on strategies for students to master concepts they missed. On a discussion of a pre-assessment, teachers discussed ways to ensure they covered missed concepts during the upcoming unit.

Support from the administration was not evident and was even mentioned to be negatively perceived by one team member. This member's perception was that the administrator saw her expectations for her students to be too high. When discussing a student's situation with an administrator, the team member said the administrator responded with, "Your expectations are too high."

\section{Discussion}

In this qualitative case study, we gathered data through interviews and observations at a high school that had implemented PLCs, but where there was little or any positive outcome with regard to the overall performance of the school. The data revealed a number of underlying problems with the conduct of the PLCs. Teachers found that the focus on data and assessments interfered with their broader need for collaboration. In particular, they lamented a lack of comprehensive discussion of teaching from the point of view of both content and method. Because the analysis focused on students who were not performing up to par, when the conversation did turn to pedagogy, it only dealt with narrow remediation of inadequately supported content knowledge. The limitation of this in-the-weeds approach was most clearly demonstrated when assessments revealed that student performance was low overall, but with no clear commonality with regard to content learning deficiencies.

Beyond the narrow focus, teachers reported other shortcomings. First, insufficient time was allocated to allow for sufficiently rich and robust work in the PLC setting. Moreover, the members of the administration appeared disengaged from the PLC process and unsupportive of its goals.

In light of these findings, it is worth remembering that there are certain components such as a sense of community, a commitment to increasing student learning, and trust that make up a successful PLC. Hawley and Rollie (2007) defined PLCs as communities committed to student learning and matters of teaching and learning. The authors observed that these communities continually question and challenge teaching practices and maintain open minds about their own teaching practices. This idea of a robust community was supported in a 2009 investigation by Cranston. Cranston found eight components of a successful PLC. Of these eight, the strongest was trust, both within the PLC team and between the principals and their staff and faculty.

To be a successful, PLC, the PLC should also include open and reflective conversation, open practice, and focus on student learning. Collaboration and shared values for student learning are keys to PLCs (Fullan, 2007). These communities should also have structures in place such as time, space, and communication. The members would be open to improvement and must trust and respect each other. The PLC should display a shared emphasis on student achievement and learning, productive collaboration, and an open teaching practice. The members would be expected to research best practices to improve student learning (Tschannen-Moran \& Tschannen-Moran, 2010).

PLCs can give teachers opportunities to question, investigate, and find solutions concerning aspects of their practice (Rahman, 2011). PLCs have a shared emphasis on student achievement, productive collaboration, and open teaching practice. However, in the present study, interviews revealed that the PLC had little to no effect on participants' teaching and lesson planning. The only benefit revealed was making some subgroups of students more noticeable as well as reinforcing the need to teach certain concepts. Some teachers even believed that the PLC had a negative effect on the way they teach, referring to the PLC as limiting their individuality and creativity in teaching and planning lessons.

The use of data-driven decision-making in PLCs can increase student achievement (Mokhtari 2009). However, teachers at the study school did not see improvement in their students' achievement in the classroom or on the high stakes test. The data that were collected such as the CFA results, did not tell, individually, what the students' strengths and weaknesses were in the subject. Nor did the data speak to the overall framework of the pedagogy or the effectiveness or the classroom management approach. Without prompts to think in different or more holistic ways, the participants were not prepared to consider whether their teaching led to improved critical thinking abilities or to more highly motivated students; therefore, the PLC did not allow for the conversation and collaborative decisions needed to help students achieve. 
The PLCs could have focused more as well on providing benefits to the participating teachers. Current literature shows that while PLCs may be used to increase student achievement, they are also effective in promoting the well-being and learning of the teachers involved (Raham, 2011).The PLC can also give the teachers opportunities to develop leadership capacities, and share their mission, vision, and goals to improve their practice.

Through the observations conducted in this study, collaboration, a key component to a successful PLC, was evident. Current literature shows that teachers who participate in an effective PLC show interdependence with one another and learn from each other (Richmond \& Monokore, 2011). Teachers in all three observations were shown to be communicating and working together to develop lessons and improve student achievement. However, in the interviews, participants noted that not enough time was given to collaborate. Participants believed the PLC was consistently about data and not about how to teach more effectively, to improve their students' achievement, or to improve their lessons. As shown by Wells (2008), teachers need the time, training, and leadership to help develop a culture where ideas on student achievement and educational practice are shared openly.

The key elements needed in the process of a successful PLC are: teacher learning and collaboration, teacher community formation, teacher confidence in content knowledge, pedagogical knowledge and practices, accountability, and sustainability (Richmond \& Monokore, 2011). PLCs should have a shared emphasis on student achievement and learning but also on collaboration and teaching practices. The members should continually research best practices to improve student learning (Tschannen-Moran \& Tschannen-Moran, 2010). Having an opportunity to question, investigate, and find a solution to aspects of the teachers' practice is also important (Rahman, 2011). The process shown at the study school involved creating a common formative assessment (CFA), giving the CFA prior to the unit of study, analyzing the data, and planning the lesson; followed by re-administering the CFA at the end of the unit and analyzing the data generated for gaps in knowledge. This narrow focus of the discussion on a single data source created blinders that prevented the PLC from serving its more comprehensive function. Indeed, that conclusion was most clearly supported by the results of the observations, which revealed that the focus in the PLCs was only on student achievement in the realm of student failures and high-stakes testing. The broader collaboration on learning and improving the pedagogical environment was not seen. Work and conversation with regard to teacher learning and collaboration was also missing from the PLC meetings.

A critical shortcoming of the PLCs examined in the current study had to with their narrow mission and definition as "Data Teams" and consequentially their constricted focus on metrics. Indeed the Data Teams usually concentrated on a single set of metrics, the results of the CFA assessments. The risks associated with use of quantitative data to establish performance metrics has been long established in a number of fields including business, science, and engineering in addition to education. In this regard, Likierman's 2009 paper, "The Five Traps of Performance Measurement," has been particularly influential. Among Likierman's traps is "putting your faith in numbers" (p. 99). As the author pointed out, the selected numbers may be of low quality or they may not capture all the information needed to make an informed decision. Hauser and Katz (1998) identified a further shortcoming of performance metrics, recognizing that managers, asked to maximize performance metrics $a, b$ and $c$, may very well do so, but often at the expense of other critical measures of organizational health and business performance, including factors such as $d, e$ and $f$. In the education world as well, this same moral and perceptual hazard no doubt applies to teachers and administrators.

Moreover, the problem may not be just the selection of the wrong metrics or too narrow a set of metrics, because quantitative data alone do not always offer all the answers. As Albert Einstein observed, "Everything that can be counted does not necessarily count; everything that counts cannot necessarily be counted" (as quoted in Calaprice, 2005).

In a recent critical retrospective, Talbert (2010) warned that PLCs that are launched just to conform with a hazy idea of best practice or to respond to an authoritarian mandate rarely result in the desired impact on student achievement. To avoid such a trap, the PLC has to do more than just consider data; it has to provide a venue for a rich and deep collaborative discussion of all aspects of the learning environment, teaching practice and outcomes. Indeed, as Bullough (2007) points out, "Powerful teacher education is more than a matter of learning about and practicing promising teaching techniques; it involves engagement in exploring, with others, pressing personal and professional problems and issues" (p. 178). Schools and school districts that want to make a real difference in learning outcomes would be well advised to invest the time, training, monitoring, feedback and support necessary to implement PLCs in their full, functional richness.

The current study adds to the existing literature by demonstrating that a so-called PLC that focuses on student performance data, largely to the exclusion of Cranston's (2009) other recommended components, was not successful. Based on these results, we can offer the following practical recommendations to make other implementations more effective. First and foremost, there must be real and continuing investment and engagement by the school administration. Administrators should invest in sufficient professional development for themselves and for the teachers, so that the entire community is prepared to understand and implement an effective PLC is all its complex richness. A big part of that investment should be in the form of time; teachers should be allocated sufficient time to get the job done. All stakeholders should engage in ongoing self-reflection and purposeful collection of feedback with regard to the functioning of the PLC. 
Certainly the PLC system that was the object of the current study would have been greatly improved if a system of continuous improvement had been implemented and sustained. Finally, a PLC should have a broad mission that incorporates analysis and discussion of the full range of the academic performance of the school, ranging from the individual student, to the classroom and on to the institution. Certainly focus on a single level and a narrow set of metrics will not achieve this goal. Finally, to have effect beyond the level of the individual classroom, these conversations at the individual team level have to feed transparently into conversation and action school-wide. Institutions that follow these recommendations will be more likely to achieve success.

\section{References}

Berry, B., Johnson, D., \& Montgomery, D. (2005). The power of teacher leadership. Educational Leadership, 62(5), 56-61.

Bullough, R.V. (2007). Professional learning communities and the eight-year study. Educational Horizons, 85(3), 168180.

Calaprice, A. (2005). The quotable Einstein. Princeton, NJ: Princeton University Press.

Cranston, J. (2009). Holding the reins of the professional learning community: Eight themes from research on principals' perceptions of professional learning communities. Canadian Journal of Educational Administration and Policy, 90, 1-22.

DuFour, R. (2004). What is a "professional learning community"? Educational Leadership, 61(8), 6-11.

DuFour, R., DuFour, R., \& Eaker, R. (2008). Revisiting professional learning communities at work: New insights for improving schools. Bloomington, IN: Solution Tree.

DuFour, R., Eaker, R., \& Many, T. (2006). Learning by doing: A handbook for professional learning communities at work. Bloomington, IN: Solution Tree.

Fullan, M. (2007). The New Meaning of Educational Change (4th ed.). New York, NY: Teachers College Press.

Hauser, J. R., \& Katz, G. M. (1998) Metrics: You are what you measure! European Management Journal, 16(5), 517-528. http://dx.doi.org/10.1016/S0263-2373(98)00029-2

Hawley, W., \& Rollie, D. L. (Eds.). (2007). The Keys to Effective Schools: Educational Reform as Continuous Improvement (2nd ed.). Thousand Oaks, CA: Corwin Press. http://dx.doi.org/10.4135/9781483329512

Likierman, A. (2009, October). The five traps of performance measurement. Harvard Business Review, 96-101.

Lodico, M. G., Spaulding, D. T., \& Voegtle, K. H. (2010). Methods in educational research: From theory to practice. San Francisco, CA: John Wiley \& Sons, Inc.

Marsh, J. (2010). How instructional coaches support data-driven decision making. Educational Policy, 24(6), 872-907. http://dx.doi.org/10.1177/0895904809341467

Merriam, S.B. (2009). Qualitative research: A guide to design and implementation. San Francisco, CA: Jossey-Bass.

Mokhtari, K., Thomas, J., \& Edwards, P. (2009). How one elementary school uses data to help raise students' reading achievement. The Reading Teacher, 63(4), 334-337. http://dx.doi.org/10.1598/RT.63.4.10

Rahman, S. (2011). Influence of professional learning community (PLC) on secondary science teachers' culture of professional practice: The case of Bangladesh. Asia-Pacific Forum on Science Learning \& Teaching, 12(1), 1-22.

Richmond, G., \& Manokore, V. (2011). Identifying elements critical for functional and sustainable professional learning communities. Science Education, 95(3), 543-570. http://dx.doi.org/10.1002/sce.20430

Talbert, J.E. (2010). Professional learning communities at the crossroads: How systems hinder or engender change. In A. Hargreaves et al. (Eds.), Second international handbook of educational change (pp. 555-571), New York: Springer. http://dx.doi.org/10.1007/978-90-481-2660-6_32

Tschannen-Moran, B., \& Tschannen-Moran, M. (2010). Executive coaching: Transforming school one conversation at a time. San Francisco, CA: Jossey-Bass. http://dx.doi.org/10.1002/9781118269510

Vescio, V., Ross, D., \& Adams, A. (2008). A review of research on the impact of professional learning communities on teaching practice and student learning. Teaching and Teacher Education, 24, 80-91. http://dx.doi.org/10.1016/j.tate.2007.01.004

Webb, R., Vulliamy, G., Sarja, A., Hämäläinen, S., \& Poikonen, P. (2009). Professional learning communities and teacher well-being? A comparative analysis of primary schools in England and Finland. Oxford Review of Education, 35(3), 405-422. http://dx.doi.org/10.1080/03054980902935008

Wells, C. (2008). A conceptual design for understanding professional learning CI, 35(2), 25-38.

\section{(cc) $\mathrm{Br}$}

This work is licensed under a Creative Commons Attribution 3.0 License. 